\title{
Correction to: The effects of soil shrinkage during centrifuge tests on SWCC and soil microstructure measurements
}

\author{
Lincui $\mathrm{Li}^{1} \cdot \mathrm{Xi}-\mathrm{An} \mathrm{Li}{ }^{1,2} \cdot \mathrm{Li} \mathrm{Wang}^{1} \cdot$ Bo Hong ${ }^{1} \cdot$ Jianfeng Shi ${ }^{1} \cdot$ Jianqiang Sun ${ }^{1}$
}

Published online: 12 November 2020

(C) Springer-Verlag GmbH Germany, part of Springer Nature 2020

Correction to: Bulletin of Engineering Geology and the Environment (2020) 79:3879-3895 https://doi.org/10.1007/s10064-020-01786-y

The original version of Fig. 7 included one incorrect image. There are two same subfigures (2b) in Fig. 7. The latter subfigure should be replace with the subfigure 2a-P. The corrected figure is included here.

The online version of the original article can be found at https://doi.org/ 10.1007/s10064-020-01786-y

Xi-An Li

dclixa@chd.edu.cn

1 College of Geology Engineering \& Geomatics, Chang'an University, Xi'an 710054, Shaanxi, China

2 Open Research Laboratory of Geotechnical Engineering, Ministry of Land and Resources, Xi'an 710054, Shaanxi, China 

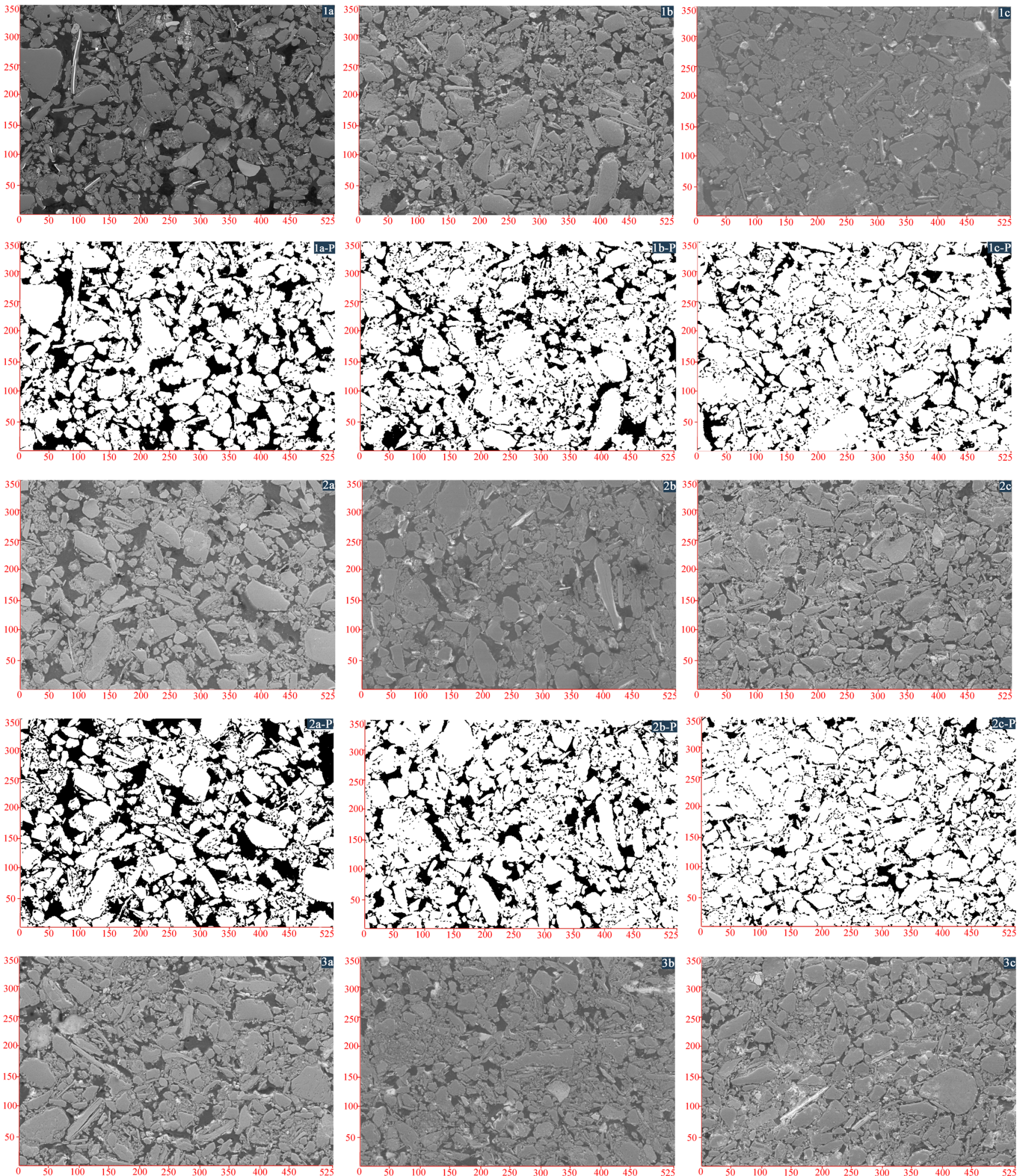

Fig. 7 SEM raw images and binary images for soil samples after different stages of centrifugation. (Specimens with densities of 1.30, 1.36, 1.46, and $1.55 \mathrm{~g} / \mathrm{cm} 3$ were numbered as 1, 2, 3, and 4, respectively. Each specimen after centrifugal rotations of $0 \mathrm{r} / \mathrm{min}, 2200 \mathrm{r} / \mathrm{min}$, and $8100 \mathrm{r}$ min was numbered $\mathrm{a}, \mathrm{b}$, and $\mathrm{c}$, respectively. $P$ means the pore distribution) 

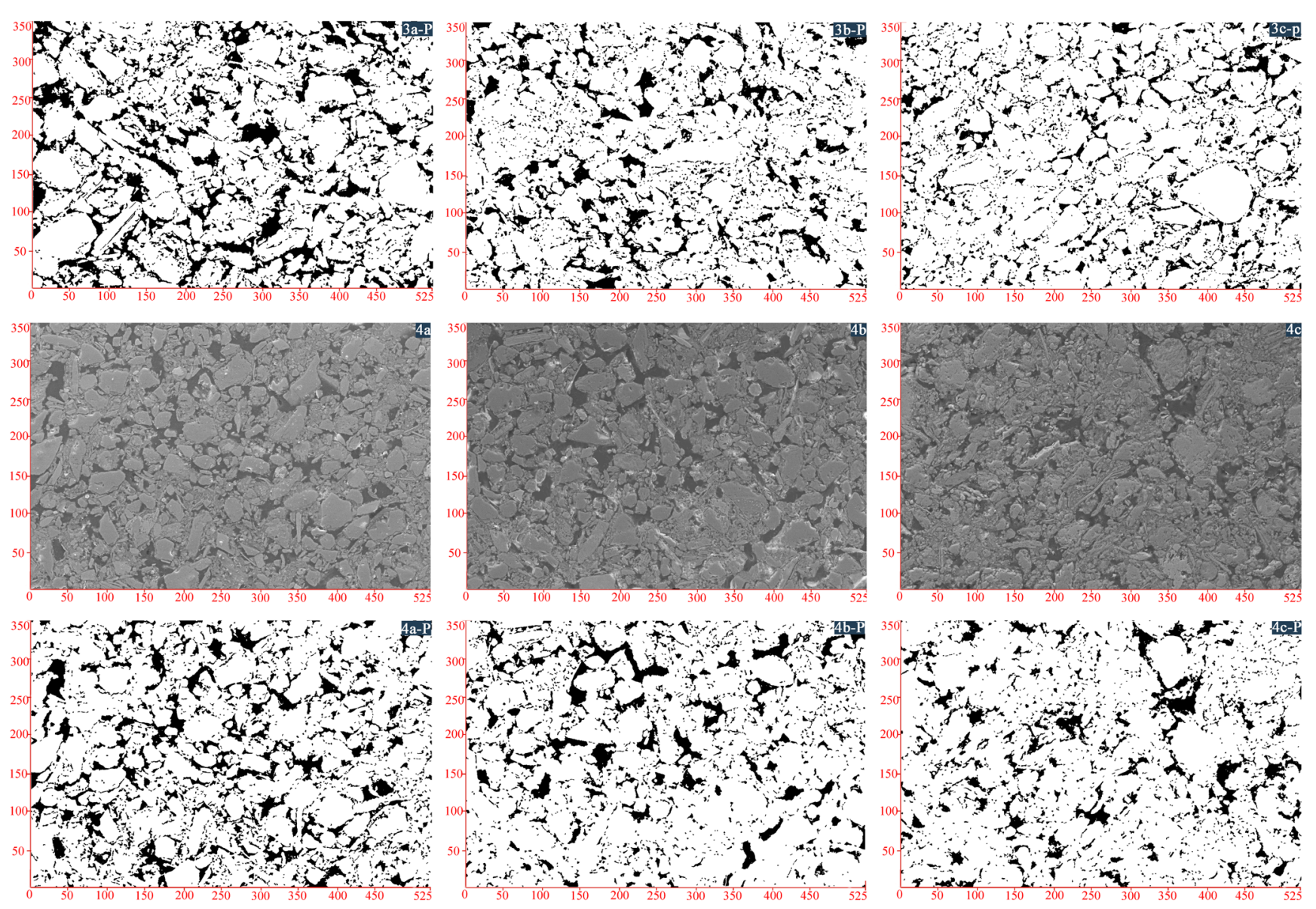

Fig. 7 (continued) 